\title{
Review Article \\ For Researchers on Obesity: Historical Review of Extra Body Weight Definitions
}

\author{
Marina Komaroff \\ Department of Epidemiology and Biostatistics, SUNY Downstate Medical Center, Brooklyn, NY 11203, USA \\ Correspondence should be addressed to Marina Komaroff; genmar2k@gmail.com
}

Received 26 January 2016; Revised 20 April 2016; Accepted 28 April 2016

Academic Editor: Francesco Saverio Papadia

Copyright ( 2016 Marina Komaroff. This is an open access article distributed under the Creative Commons Attribution License, which permits unrestricted use, distribution, and reproduction in any medium, provided the original work is properly cited.

\begin{abstract}
Rationale. The concept of obesity has been known since ancient world; however, the current standard definition of obesity was endorsed only about a decade ago. There is a need for researches to understand multiple approaches to defining obesity and how and why the standard definition was developed. The review will help to grasp the complexity of the problem and can lead to novel hypotheses in obesity research. Objective. This paper focuses on the objective to understand historical background on the development of "reference and standard tables" of weight as a platform for normal versus abnormal body weight definition. Methods. A systematic literature review was performed to chronologically summarize the definition of body weight from time of Hippocrates till the year of 2010. Conclusion. This paper presents the historical background on the development of "reference and standard tables" of weight as a platform for normal versus abnormal body weight definition. Knowledge of historical approaches to the concept of obesity can motivate researchers to find new hypotheses and utilize the appropriate obesity assessments to address their objectives.
\end{abstract}

\section{"The secret of getting ahead is getting started."}

Mark Twain

\section{Introduction}

In 2001, "The Surgeon General's Call to Action to Prevent and Decrease Overweight and Obesity" set up the first objective as "to promote the recognition of overweight and obesity as major public health problem" in the United States [1]. The Surgeon General's Call to Action recognized that overweight and obesity have reached nationwide epidemic and underscored that the urgent goals are to prevent and treat the obesity and chronic diseases associated with obesity $[1,2]$.

In 2001, Food and Drug Administration and National Institutes of Health developed the Healthy People 2010 program that was committed to prevention and treatment of overweight and obesity to reduce chronic diseases associated with diet and weight [3]. In 2010 report, Healthy People 2010 summarized that the age-adjusted proportion of healthy (body mass index (BMI) $<25.0 \mathrm{~kg} / \mathrm{m}^{2}$ ) adults (age $\geq 20$ years) decreased from $42 \%$ in $1988-94$ to $31 \%$ in 2005-08; and the proportion of obese (BMI $\geq 30.0 \mathrm{~kg} / \mathrm{m}^{2}$ ) increased from
$23 \%$ to $34 \%$ for the same period of time [3]. The experts concluded that the ten-year goal to prevent and treat the obesity was not met [3]. Instead, the nation was moving away from the objective to promote health and reduce chronic diseases associated with diet and weight [3]. This underscores the extent of the problem and urgency to seek a solution.

Clear understanding of the concept of obesity and its measurements should be the first step for successful research in obesity arena. The topic of obesity is extremely complex. Even though enormous research has been done to discover the causes of obesity, there is still no clear statement if obesity is exposure or outcome. For example, there is still a question if psychological depression causes obesity or obesity is a cause for psychological depression. This paper does not declare any perception on obesity and does not aim to cover causes and/or consequences of obesity. It aims to unfold all points of view on the obesity concept and definition through the chronological review of its development. 


\section{What Is Obesity}

Hippocrates (460 BC-370 BC) described the health for human body as a balance of four humors (fluids): blood, black bile, yellow bile, and phlegm, and any deficiencies or extras were considered causes of diseases [4]. Obesity was defined as the surplus of humors [4]. For a big part of human history extra weight was considered as an indication of good health, as well as wealth and prosperity. Hippocrates was the first who realized that obesity leads to infertility and early mortality [5]. It took more than two thousand years to test his hypotheses scientifically and evaluate how "surplus of humors" relates to different health outcomes and early deaths.

The weight measurement and evaluation criteria are necessary to define overweight and obesity. In 1885, introduction of a penny scale first in Germany then in the United States allowed measuring the body weight to the nearest pound [6]. Since then a new era for weight assessments and search for "healthy" weight started. In the beginning of 20th century a low body weight was a concern because of threat of pneumonia and tuberculosis especially for young and underweight adults [7]. Healthy weight became the criteria for the individual's enrollment into the insurance policies [712]. The question of "ideal" weight and the acceptable level of deviation from "ideal" became the most important questions for insurance companies [7-12]. Overweight was defined as weight that exceeded the threshold from the reference value, where reference value was derived from the distribution of population. Based on observed association of body weight with mortality, the Metropolitan Life Insurance Company (MLIC) was able to develop the standard tables for "ideal" (MLIC 1942) $[9,10]$ and then "desirable" weight (MLIC 1959) $[11,12]$ and finally just "height to weight" tables (MLIC 1983) $[13,14]$. Those standard tables became the platform for development of current definition for underweight, normal, overweight, and obese individuals based on the body mass index (BMI) cut-offs $[15,16]$.

\section{Measurements of Obesity}

One of the ways to assess overweight and obesity is to compare the individual's weight versus the reference value defined as the average population weight; and another way is to compare it with the weight standards that derived from the relationship between body weight and mortality or morbidity outcomes. The background of development reference or "average" tables is outlined in Section 3.1. The process of how tables of "average" weight were transformed into the "ideal" weight standards tables based on the lowest rate of mortality is described in Section 3.2. The historical background of development of both is summarized in Table 3.

3.1. "Normal Man" and the "Average" Weight Tables. Belgian astronomer and mathematician Adolphe Quetelet (17961874) was fascinated by the probability theory and passionately applied probability calculus into the physical characteristics of human body [19]. His idea was to demonstrate that normal Gaussian distribution can be applied to physical attributes of humans, and he was looking for the "norm" [19].
TABLE 1: Table of height and weight [17, page 139].

\begin{tabular}{lcc}
\hline & Height & Weight (pounds) \\
Feet & Inches & 120 \\
\hline 5 & 1 & 125 \\
5 & 2 & 130 \\
5 & 3 & 135 \\
5 & 4 & 140 \\
5 & 5 & 143 \\
5 & 6 & 145 \\
5 & 7 & 148 \\
5 & 8 & 155 \\
5 & 9 & 160 \\
5 & 10 & 165 \\
5 & 11 & 170 \\
6 & $\infty$ & \\
\hline
\end{tabular}

In 1831-32, Quetelet conducted what has been considered the first cross-sectional study of newborns and children based on their growth in height and weight [19]. Adolphe Quetelet's cross-sectional studies of human development revealed that weight grows as a cube of baby's height during the first year of life and then as a square of height until puberty and almost stops after the age of twenty-five [19]. In 1835, Quetelet published a book entitled “A Treatise on Man and the Development of His Aptitudes" with the conclusion that individual's weight increases as a function of the square of their height and introduced the anthropometric index as weight in kilograms divided by the square of the height in meters which is now known as Quetelet Index [19, years 1835 and 1842, English translation]. Adolphe Quetelet was the first who developed the table of the "average weight" at ages 20, $30,40,50$, and 60 for a sample of Belgian men and women $[7,19]$.

In 1846, Hutchinson, a British surgeon, published a table of the "average" weights of 30-year-old men for each inch of height from 5 feet 1 inch to 6 feet at age of 30 based on statistics of 2,650 Englishmen [7,20]. This table became the reference for English population and was used by the life insurance companies as a guide to evaluate applicants $[7,17]$.

In 1867, Fish published "The Agent's Manual of Life Assurance" by the Mutual Life Insurance Company of New York [17]. Table of height and weight (Table 1 [17, page 139]) adopted English reference for American people based on reviews from Minturn Post and Isaac L. Kip who were medical examiners for the Mutual Life Insurance Company of New York [17]. The reference table for American population "differs slightly" from the English ones set by Hutchinson and offered "what the best authorities regard as the most desirable proportion of the height of individuals to their weight" [17].

In 1889, the Actuarial Society of America and the Association of Life Insurance Medical Directors of America were founded which made possible a uniformed approach to the industry-wide height and weight tables [7]. In 1912, MedicoActuarial Mortality Investigation published the statistics of height and weight of insured people and set up a goal "to provide an accurate Standard Table of Heights and Weights and to determine the influence of build on longevity" [7]. 
The whole process of development of standard weight tables with major milestones is summarized in Section 3.2 and Table 3.

3.2. Standard Tables of "Ideal" Weight. First tables of "ideal" weights were developed by Dublin and Lotha (1882-1969), a statistician and vice president of the Metropolitan Life Insurance Company (MLIC) [8]. The data from approximately four million MLIC policyholders from 1911 to 1935 were utilized [8]. The main criterion for "ideal" weight was longevity [8]. Dublin and Lotha grouped policyholders into categories by sex, height, and weights; but they could not fit the numbers into normal curve until they divided the studied population further into the three types of body frames: small, medium, and large [8]. From the prospective of insurance, the "bad weight" was considered to be $20-25 \%$, with morbid obesity at $70-100 \%$ above the "ideal" weight for a given frame [8]. The "1942-43 Metropolitan Height and Weight Tables" were created based on Dublin and Lotha work and became the national standards for "ideal" body weight $[9,10]$. Those tables were close representation of the longevity of American population but contained little information about trend and causes of mortality $[9,10]$.

In 1959, "The Build and Blood Pressure Study" was conducted by the Society of Actuaries with collaboration of 26 insurance companies to determine the mortality of insured persons according to variations in body build and blood pressure $[12,14]$. The weights were derived from data of people with lowest mortality who were insured between 1935 and 1953 and followed to 1954 in the United States and Canada [12]. Measured heights and weights were of people wearing "indoor clothing and shoes" and included 20\% of self-reported values [12]. "Frame size" for this study was not based on measurement of skeletal dimensions but arbitrarily divided the distribution of relative weights on the assumption that skeletal size was associated with a person's position in that distribution [12]. The association between body weight and mortality, particularly from cardiovascular diseases, was demonstrated, and MLIC 1959 weight tables were created, where "ideal weight" was replaced by the "desirable weight" [11].

In 1973, the Fogarty International Center Conference on Obesity recommended guidance for body weight based on the updates from the MLIC 1959 "desirable" weight tables [21]. The updates meant creation of "acceptable range" of weight for a particular height by the rule that for men and women for each inch of height set up the range of weight where the weight in the lower limit of the small frame and the weight in the upper limit of the large frame form the range of weights for the standards [21,31]. The "acceptable range" for weight was converted into the suggested body mass index as 20.1-25.0 for men and 18.7-23.8 for women [21]. These tables were adopted in the report of obesity by Royal College of Physicians in 1983 [31].

In 1979, the second study of "The Build and Blood Pressure Study" produced the revised tables based on the mortality of insured people from 1950 to 1972 where "desirable" weights were higher than those in previous study [14]. Based on the data from new study, the MLIC 1959 tables
TABLE 2: Range of acceptable body weight [18].

\begin{tabular}{lcc}
\hline Height (feet-inches) & Men (pounds) & Women (pounds) \\
\hline $4^{\prime} 10^{\prime \prime}$ & & $92-119$ \\
$4^{\prime} 11^{\prime \prime}$ & & $96-129$ \\
$5^{\prime} 0^{\prime \prime}$ & & $96-125$ \\
$5^{\prime} 1^{\prime \prime}$ & $112-141$ & $99-128$ \\
$5^{\prime} 2^{\prime \prime}$ & $115-144$ & $102-131$ \\
$5^{\prime} 3^{\prime \prime}$ & $118-148$ & $105-134$ \\
$5^{\prime} 4^{\prime \prime}$ & $121-152$ & $108-138$ \\
$5^{\prime} 5^{\prime \prime}$ & $124-156$ & $111-142$ \\
$5^{\prime} 6^{\prime \prime}$ & $128-161$ & $114-146$ \\
$5^{\prime} 7^{\prime \prime}$ & $132-166$ & $118-150$ \\
$5^{\prime} 8^{\prime \prime}$ & $136-170$ & $122-154$ \\
$5^{\prime} 9^{\prime \prime}$ & $140-174$ & $126-150$ \\
$5^{\prime} 10^{\prime \prime}$ & $144-179$ & $130-163$ \\
$5^{\prime} 11^{\prime \prime}$ & $148-184$ & $134-168$ \\
$6^{\prime} 0^{\prime \prime}$ & $152-189$ & $138-173$ \\
$6^{\prime} 1^{\prime \prime}$ & $156-194$ & \\
$6^{\prime} 2^{\prime \prime}$ & $160-199$ & \\
$6^{\prime} 3^{\prime \prime}$ & $164-204$ & \\
$6^{\prime} 4^{\prime \prime}$ & & \\
\hline
\end{tabular}

Note: height without shoes and weight without clothes.

for "desirable" weight were replaced by MLIC 1983 tables of "height and weight" [13].

Overweight and obesity are the nutrition-related disorders which are caused by the accumulation of extra fat as was stated by the Department of Health and Human Services (HHS) and the Department of Agriculture (USDA) which were responsible for issuing the "Dietary Guidelines for Americans" in 1980 and for updating the document every 5 years [32]. The goal of the document was to provide nutritional and dietary information and guidance for general public. In 1980, US Department of Agriculture and US Department of Health, Education and Welfare published the first edition of nutritional "Dietary Guidelines for Americans" and advised the public based on current knowledge of the relationship of diet to health and disease [18]. The guidance included a table with suggested body weight based on the tables recommended by Fogarty International Center Conference on Obesity with the adjustments for height and weight [18]. Adjustment for height was done as 1 or 2 inches $(2.54$ and $5.08 \mathrm{~cm}$ ) for shoes and $10 \mathrm{lb}-6 \mathrm{lb}$ for clothes (Table 2) $[18,33$, 34].

The National Institutes of Health Consensus Development Conference on the Health Implications of Obesity applied criteria for defining overweight, severe overweight, obesity, and severe obesity to the National Health and Nutrition Examination Survey 1976-80 (NHANES II) data [22]. "Overweight" was defined by a BMI (body mass index = weight in kilograms divided by weight in meters squared) $\geq 85$ th percentile, with "severe overweight" $\geq 95$ th percentile of 20-year-old to 29-year-old men and women [22]. "Obesity" and "severe obesity" were defined using the same criteria: only the sum of the triceps and subscapular skinfold thicknesses instead of the body mass index [22]. The 


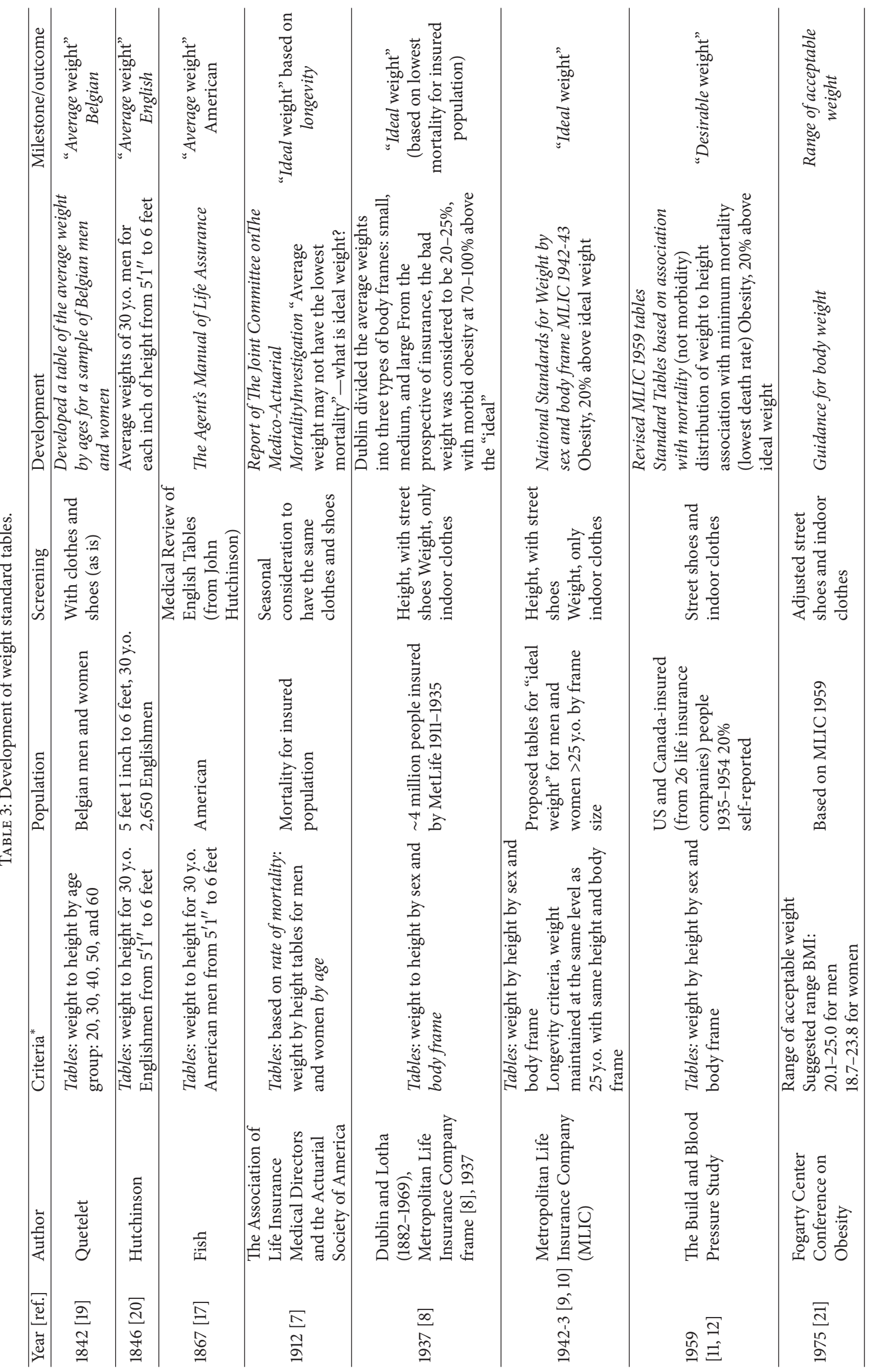




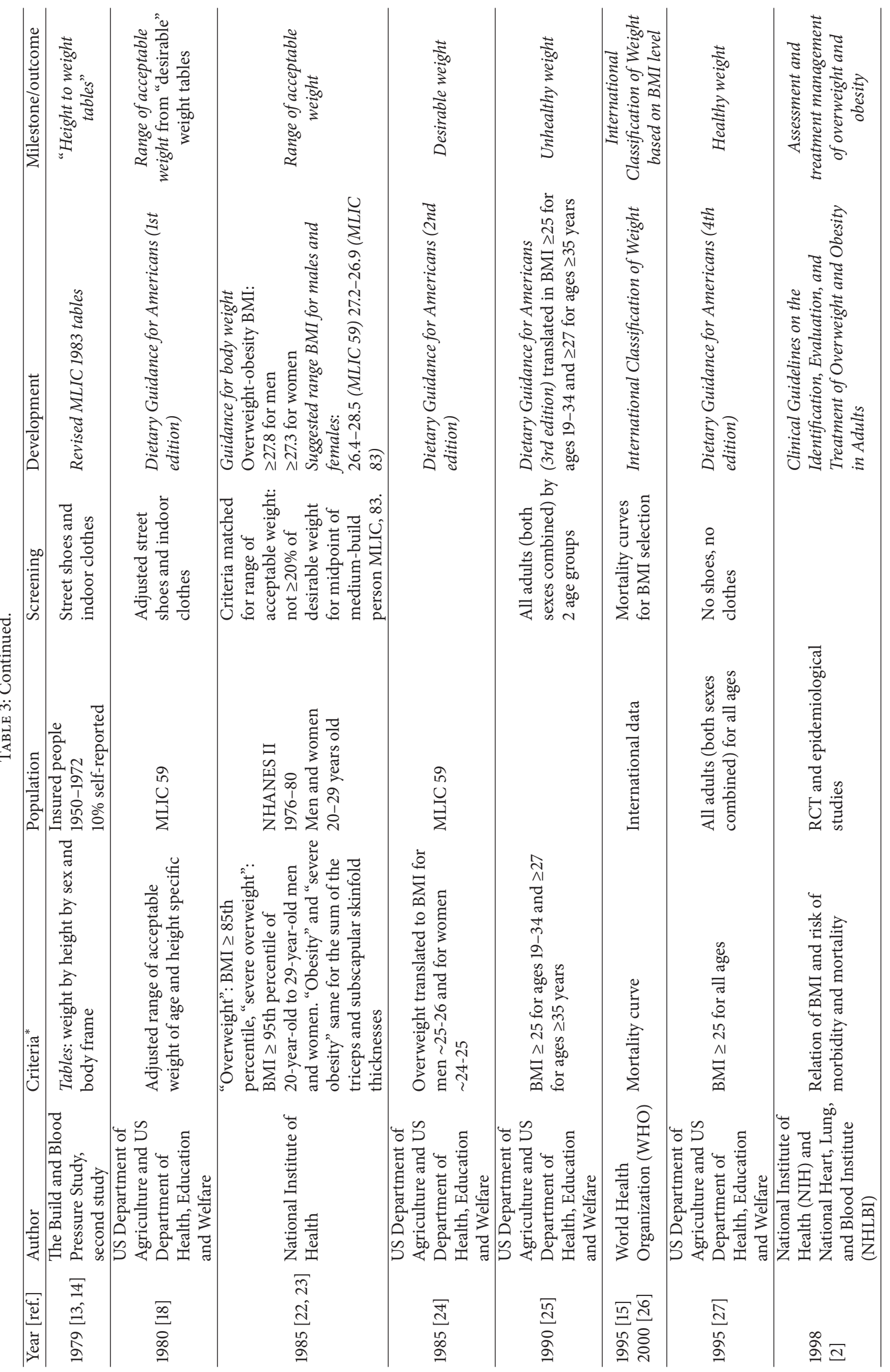




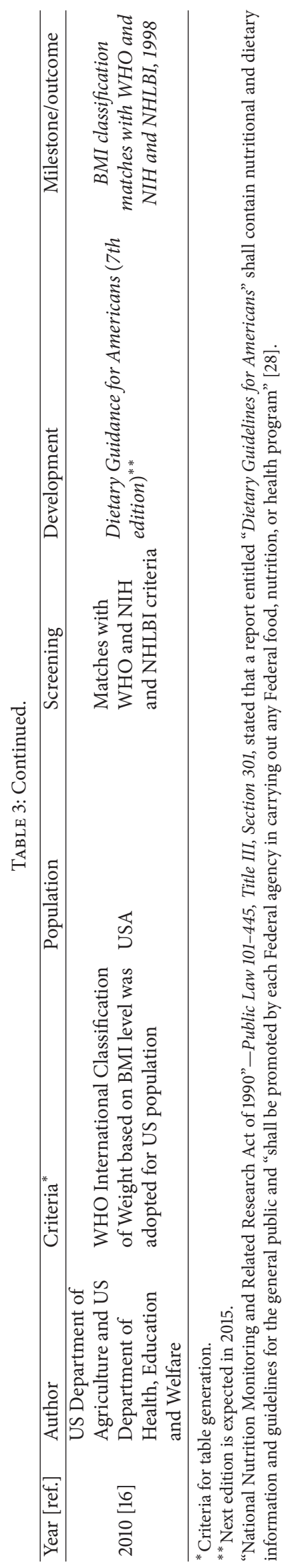


numbers came to the criteria of defining "overweight" as BMI $\geq 27.8 \mathrm{~kg} / \mathrm{m}^{2}$ for men and BMI $\geq 27.3$ for women [22]. These criteria matched with $20 \%$ or more above the "desirable" weight in the MLIC 1983 tables (from midpoint of the range for a medium-build person) [22]. These definitions became widely accepted as the standards [22]. Nevertheless, numbers for ranges of acceptable "normal" BMI were different from those based on the version of standard tables, for example, for MLIC 1959, 26.4 (men) and 28.5 (women), and for MLIC 1983, 27.2 (men) and 26.9 (women) [23]. Moreover, the recommended requirement differed from the guidelines set up by Fogarty Center and the Royal College of Physicians [21, 35]. Such discrepancies in the guidance pointed out the technical problems of weight to height tables: the discrepancies of measurements (shoes, clothes, and approximately $20 \%$ selfreported data in MLIC 1959 and 10\% in MLIC 1983) and population selection [35]. It brought up an urgent need to standardize definition of overweight and obesity and the search for weight to height index of body weight started.

In 1985, the Department of Health and Human Services (HHS) and the Department of Agriculture (USDA) issued the second edition of "Dietary Guidelines for Americans" [24]. That document used the "desirable" weight to height tables from MLIC 1959 and translated the numbers into overweight level of BMI for men 25-26 and for women 24-25 [24, 34]. In the 1990 third edition, tables for men and women were combined into one and presented by two age groups where "unhealthy" weight was translated into BMI $\geq 25$ for ages 1934 and $\geq 27$ for ages $\geq 35$ years $[25,34]$.

In 1990, the "National Nutrition Monitoring and Related Research Act of 1990," Public Law 101-445, Title III, Section 301, stated that a report entitled "Dietary Guidelines for Americans" shall contain nutritional and dietary information and guidelines for the general public and be published at least every five years [28]. Each such report "shall be promoted by each Federal agency in carrying out any Federal food, nutrition, or health program" [28]. Basically, the law stated that the definition of healthy weight or overweight from the Dietary Guidelines for Americans should be used by the constituent Federal agencies [28].

In Geneva, in 1995, WHO Expert Committee on Physical Status published technical report: The Use and Interpretation of Anthropometry [15]. It was acknowledged that the basic anthropometry measurements of human body are weight and height [15]. It was recommended to combine two basic measurements: weight and height into the body mass index (weight/height ${ }^{2}$ ) or ponderal index (weight/height ${ }^{3}$ ) for adults; and three anthropometric indexes with consideration of age were described for children: weight for height, height for age, and weight for age [15]. The WHO Expert Committee on Physical Status proposed to classify different levels of BMI with cut-off points of 25,30 , and 40 based on "arbitrary method of association between BMI and mortality" [15]. WHO Expert Committee on Physical Status referenced the meta-analysis performed by Troiano et al. which included 17 studies with 37 substudies with 350,000 men and $>38000$ deaths plus six studies with 12 substudies with 250,000 women and 13700 deaths and presented the U-shape mortality rates that sharply increased when $\mathrm{BMI}<18.5$ and
TABLE 4: International classification of adults based on body mass index.

\begin{tabular}{lcc}
\hline Classification & \multicolumn{2}{c}{ BMI $\left(\mathrm{kg} / \mathrm{m}^{2}\right)$} \\
& Cut-off points & Additional cut-off points \\
\hline Underweight & $<18.50$ & $<18.5$ \\
Severe thinness & $<16.00$ & $<16.0$ \\
Moderate thinness & $16.00-16.99$ & $16.00-16.99$ \\
Mild thinness & $17.00-18.49$ & $17.00-18.49$ \\
Normal & $18.50-24.99$ & $18.50-22.99$ \\
Overweight & $\geq 25.00$ & $23.00-24.99$ \\
Preobese & $25.00-29.99$ & $\geq 25.00$ \\
Obese & $\geq 30.00$ & $25.00-27.49$ \\
Class I & $30.00-34.99$ & $27.50-29.99$ \\
Class II & $35.00-39.99$ & $32.50-34.99$ \\
Class III & $\geq 40.00$ & $35.00-37.49$ \\
\hline
\end{tabular}

Source: from WHO, 1995, WHO, 2000, and WHO, $2004[15,26,29,30]$.

$>30.0 \mathrm{~kg} / \mathrm{m}^{2}$ with the acceptable BMI range as 18.5-25.00 [15, page 322]. The WHO experts underscored that the cut-offs were chosen arbitrarily based on the "visual inspection of the relationship between BMI and mortality" [15] curve: for example, "the cut-off of 30 is based on the point of flexion of the curve" [15]. The authors suggested that this method should be revised in the future in terms of BMI association with health risk [15].

In 1995, the next step was taken to combine not just both sexes but also age groups where "healthy" weight was translated in BMI $\geq 25$ for all adults in the fourth edition of "Dietary Guidelines for Americans" [27]. The report used WHO criteria for publishing healthy weight ranges for men and women by each inch of height [27]. The edition was very important because it led to publishing the prevalence and trends on overweight (BMI $\geq 25$ ), preobese (BMI: 25.0-29.9), class 1 (BMI: $30.0-34.9$ ), class 2 (BMI: 35.0-39.9), and class 3 (BMI $\geq 40.0)$ obese in the United States data from 1960 to 1994 (NHANES I, II, and III) for first time to facilitate comparison with international data [2].

Clinical Guidelines on the Identification, Evaluation, and Treatment of Overweight and Obesity in Adults (NIH, September 1998) defined overweight as a body mass index (BMI) of 25 to $29.9 \mathrm{~kg} / \mathrm{m}^{2}$ and obesity as a BMI of $\geq 30 \mathrm{~kg} / \mathrm{m}^{2}$ [2]. The panel of experts came to this classification based on evidence from approximately 394 randomized controlled trials (RCTs) and multiple observational studies about BMI and risk of morbidity and mortality [2]. The classification matched with one suggested by WHO $[2,15]$.

In 2000, World Health Organization (WHO) defined overweight and obesity as "the disease in which excess body fat has accumulated to such an extent that health may be adversely affected" [26] and underscored that the practical definition of obesity is based on the level of body mass index (BMI) $[15,26]$. The most recent version of international 
TABLE 5: Overweight and obese children and adolescents [16].

\begin{tabular}{lcr}
\hline Category & $\begin{array}{c}\text { Children and adolescents (BMI for age } \\
\left.\text { percentile range }{ }^{*}\right)\end{array}$ & Adults (BMI) \\
\hline Underweight & Less than the 5 th percentile & $18.5 \mathrm{~kg} / \mathrm{m}^{2}$ \\
Healthy weight & 5th percentile to less than the 85 th percentile & 18.5 to $24.9 \mathrm{~kg} / \mathrm{m}^{2}$ \\
Overweight & 85 th percentile to less than the 95 th percentile & 25.0 to $29.9 \mathrm{~kg} / \mathrm{m}^{2}$ \\
Obese & Equal to or greater than the 95 th percentile & $30.0 \mathrm{~kg} / \mathrm{m}^{2}$ or greater \\
\hline
\end{tabular}

${ }^{*}$ Growth charts are available at http://www.cdc.gov/growthcharts/.

classification for adults developed by WHO is presented in Table $4[15,26]$.

BMI has never been a perfect index for children because it correlates with height. In the United States, Centers for Disease Control and Prevention (CDC) 2000 used five nationally representative surveys to develop BMI charts for children in the United States: the National Health Examination Surveys (NHES) II and III in the 1960s, the National Health and Nutrition Examination Surveys (NHANES) I and II in the 1970s, and NHANES III for the period of 19881994. Those charts included gender-specific BMI by single month of age curves of growth. Currently they are used in the United States for children who are 2-19 years old to define "overweight" as BMI $\geq 95$ th percentile or "at risk for overweight" if BMI is between 85th and 95th percentiles $[26,36]$.

International surveys of six large and nationally representative cross-sectional growth studies from Brazil, Great Britain, Hong Kong, Netherlands, Singapore, and the United States were used by International Obesity Task Force (IOTF) to establish the cut-off points for overweight and obese among children and adolescents [37]. In summary, participants of IOTF agreed to link childhood overweight and obesity to the cut-offs for adults. Based on each of the surveys, percentile curves were drawn in such a way that they passed through BMI cut-off points of 25 and $30 \mathrm{~kg} / \mathrm{m}^{2}$ at age of 18 years, and the resulting curves were averaged by age and gender to provide cut-off points for 2 through 18 years of age [37]. This way less arbitrary and more internationally based cut-offs were proposed [37].

In the current edition of Dietary Guidelines for Americans, 2010, the BMI cut-offs are consistent with internationally recommended [16]. By the Public Law 101-445, Title III, Section 301, all Federal agencies have made the transition to define overweight and obesity as a BMI consistent with recommendations in the current edition of Dietary Guidelines for Americans $[16,28]$. The table of weight category based on BMI level from Dietary Guidelines for Americans, 2010, is presented in Table 5 [16].

\section{Summary}

There is nationwide and global epidemic of obesity. As the first step to conquer a problem, the concept of obesity should be clearly understood through the historical process that led to the worldwide accepted standard definition. This paper presents the history of developing current standard definition of overweight and obesity. Understanding the roots will lead to the successful research on obesity with a goal to defeat national and global epidemic.

\section{Competing Interests}

The author declares that there are no competing interests.

\section{Acknowledgments}

The author thanks Drs. Michael Szarek, Michael Walsh, and Elizabeth Helzner for assistance with development of this proposal.

\section{References}

[1] U.S. Department of Health and Human Services, The Surgeon General's Call to Action to Prevent and Decrease Overweight and Obesity, U.S. Department of Health and Human Services, Public Health Service Office of the Surgeon General, Rockville, Md, USA, 2001.

[2] National Institutes of Health, "Clinical guidelines on the identification, evaluation, and treatment of overweight and obesity in adults-the evidence report," Obesity Research, vol. 6, supplement 2, pp. 51S-209S, 1998.

[3] "Nutrition and overweight," in Healthy People 2010, chapter 19, pp. 1-15, Food and Drug Administration, National Institutes of Health, Hyattsville, Md, USA, 2001, http://www.cdc.gov/nchs/ data/hpdata2010/hp2010_final_review_focus_area_19.pdf.

[4] H. Christopoulou-Aletra and N. Papavramidou, "Methods used by the Hippocratic physicians for weight reduction," World Journal of Surgery, vol. 28, no. 5, pp. 513-517, 2004.

[5] D. Haslam, "Obesity: a medical history," Obesity Reviews, vol. 8, supplement 1, pp. 31-36, 2007.

[6] H. Schwartz, Never Satisfied: A Cultural History of Diets, Fantasies, and Fat, The Free Press, New York, NY, USA, 1986.

[7] Medico-Actuarial Mortality Investigation, vol. 1, Association of Life Insurance Medical Directors; The Actuarial Society of America, New York, NY, USA, 1912.

[8] L. I. Dublin and A. J. Lotha, Twenty-Five Years of Health Progress: A Study of the Mortality Experience among the Industrial Policyholders of the Metropolitan Life Insurance Company, 1911 to 1935, Metropolitan Life Insurance, New York, NY, USA, 1937.

[9] Ideal weight for women. Statistical bulletin of the Metropolitan Life Insurance Company, 1943.

[10] Metropolitan Life Insurance Company, "Ideal weights for men," Statistical Bulletin of the Metropolitan Life Insurance Company, vol. 23, pp. 6-8, 1942. 
[11] Metropolitan Life Insurance Company, "New weight standards for men and women," Statistical Bulletin-Metropolitan Life Insurance Company, vol. 40, pp. 1-4, 1959.

[12] Build and Blood Pressure Study, vol. 1, Society of Actuaries, Chicago, Ill, USA, 1959.

[13] Metropolitan Life Insurance Company, "Metropolitan height and weight tables," Statistical Bulletin (Metropolitan Life Insurance Company), vol. 64, pp. 1-19, 1983.

[14] Build Study 1979, Society of Actuaries and Associations of Life Insurance Medical Directors, Chicago, Ill, USA, 1980.

[15] WHO, "Physical status: the use and interpretation of anthropometry," Report of a WHO Expert Committee. WHO Technical Report Series 854, World Health Organization, Geneva, Switzerland, 1995.

[16] US Department of Agriculture and US Department of Health and Human Services, Dietary Guidelines for Americans, 2010, US Government Printing Office, Washington, DC, USA, 2010.

[17] H. C. Fish, The Agent's Manual of Life Assurance, Mutual Life Insurance Company of New York, New York, NY, USA, 1867.

[18] US Department of Agriculture and US Department of Health and Human Services, Nutrition and Your Health: Dietary Guidelines for Americans, US Government Printing Office, Washington, DC, USA, 1980.

[19] M. A. Quetelet, A Treatise on Man and the Development of His Faculties, William and Robert Chambers, Edinburgh, UK, 1842.

[20] J. Hutchinson, "On the capacity of the lungs, and on the respiratory functions, with a view of establishing a precise and easy method of detecting disease by the spirometer," MedicoChirurgical Transactions (London), vol. 29, pp. 137-161, 1846.

[21] "Obesity in perspective," in Fogarty International Center. Series on Preventive Medicine, G. Bray, Ed., vol. 2 of DHEW Publication no (NIH) 75-708, part 1, 1975, https://searchworks.stanford.edu/ view/2520869.

[22] "Health implications of obesity: National Institutes of Health consensus development conference statement," Annals of Internal Medicine, vol. 103, no. 1, pp. 147-151, 1985.

[23] "Health implications of obesity. National institutes of health consensus development conference statement," Annals of Internal Medicine, vol. 103, no. 6, part 2, pp. 1073-1077, 1985.

[24] US Department of Agriculture and US Department of Health and Human Services, Nutrition and Your Health: Dietary Guidelines for Americans, Home and Garden Bulletin no. 232, US Government Printing Office, Washington, DC, USA, 1985.

[25] US Department of Agriculture and US Department of Health and Human Services, Nutrition and Your Health: Dietary Guidelines for Americans, vol. 232 of Home and Garden Bulletin, US Government Printing Office, Washington, DC, USA, 1990.

[26] WHO, "Obesity: preventing and managing the global epidemic," WHO Technical Report Series 894, World Health Organization, Geneva, Switzerland, 2000.

[27] US Department of Agriculture and US Department of Health and Human Services, Nutrition and Your Health: Dietary Guidelines for Americans, US Government Printing Office, Washington, DC, USA, 1995.

[28] Congressional Record. Public law 101-445: National Nutrition Monitoring and Related Research Act of 1990, October, 1990. [Congressional Record, vol 136, House Report no. 101 (Committee on Agriculture)], 1990.

[29] WHO/IASO/IOTF, The Asia-Pacific Perspective: Redefining Obesity and Its Treatment, Health Communications, Melbourne, Australia, 2000.
[30] WHO Expert Consultation, "Appropriate body-mass index for Asian populations and its implications for policy and intervention strategies," The Lancet, vol. 363, no. 9403, pp. 157-163, 2004.

[31] J. Yudkin, "Obesity: a report of the royal college of physicians," Journal of the Royal Society of Medicine, vol. 76, no. 6, pp. 531$532,1983$.

[32] The Secretary of Health and Human Services, Charter 2015 Dietary Guidelines Advisory Committee, The Secretary of Health and Human Services, Washington, DC, USA, 2015.

[33] W. F. Kemsley, W. Z. Billewicz, and A. M. Thomson, "A new weight-for-height standard based on British Anthropometric data," British Journal of Preventive \& Social Medicine, vol. 16, pp. 189-195, 1962.

[34] R. J. Kuczmarski and K. M. Flegal, "Criteria for definition of overweight in transition: background and recommendations for the United States," The American Journal of Clinical Nutrition, vol. 72, no. 5, pp. 1074-1081, 2000.

[35] R. J. Jarrett, "Is there an ideal body weight?" British Medical Journal, vol. 293, no. 6545, pp. 493-495, 1986.

[36] K. M. Flegal, C. J. Tabak, and C. L. Ogden, "Overweight in children: Definitions and interpretation," Health Education Research, vol. 21, no. 6, pp. 755-760, 2006.

[37] T. J. Cole, M. C. Bellizzi, K. M. Flegal, and W. H. Dietz, "Establishing a standard definition for child overweight and obesity worldwide: international survey," The British Medical Journal, vol. 320, no. 7244, pp. 1240-1243, 2000. 


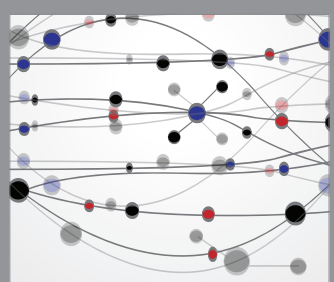

The Scientific World Journal
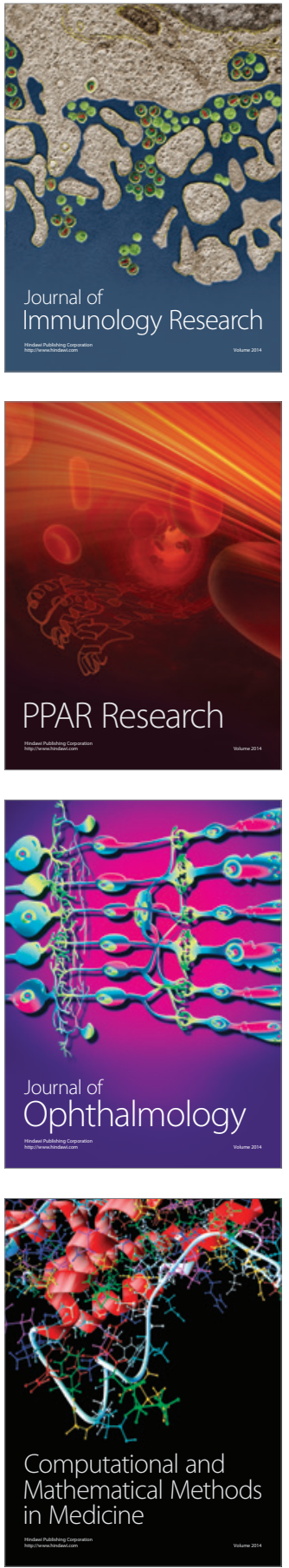

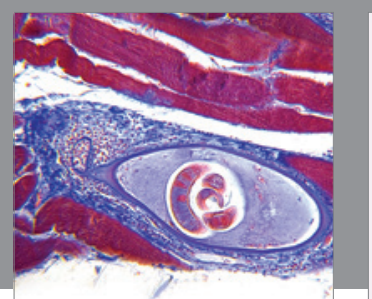

Gastroenterology Research and Practice

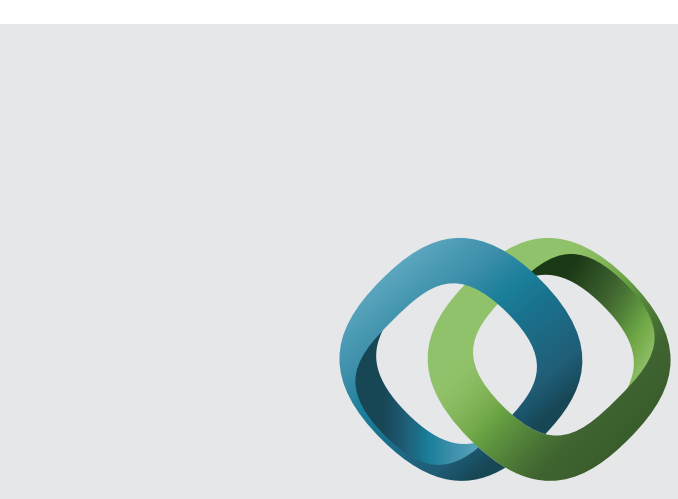

\section{Hindawi}

Submit your manuscripts at

http://www.hindawi.com
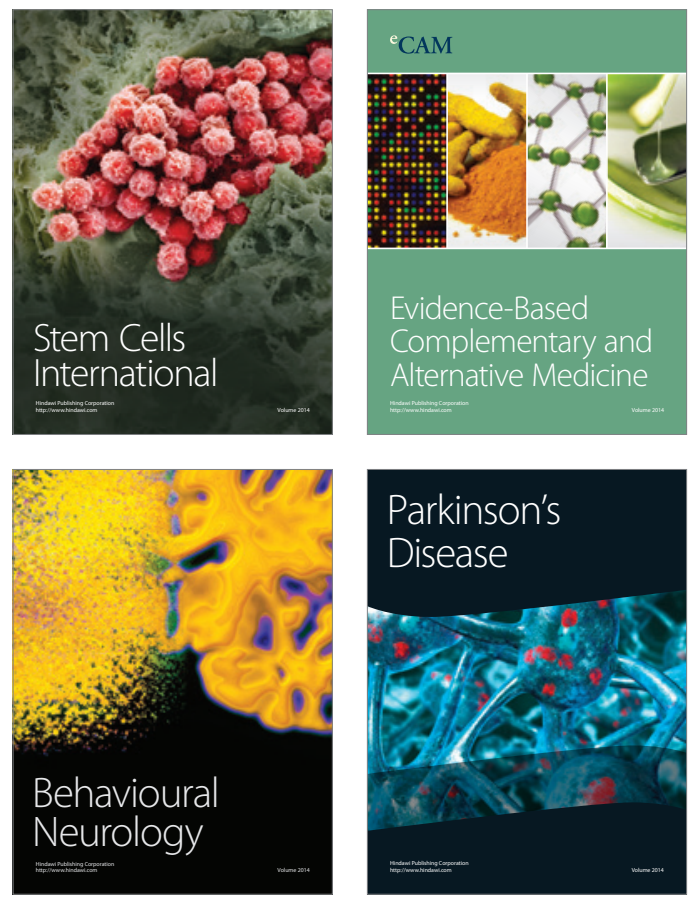
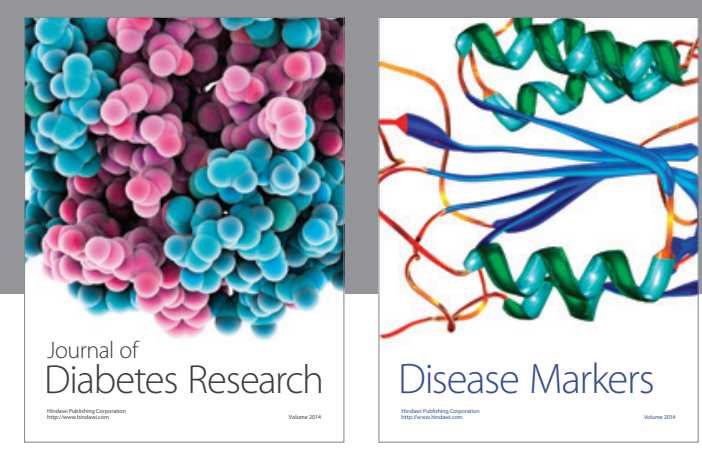

Disease Markers
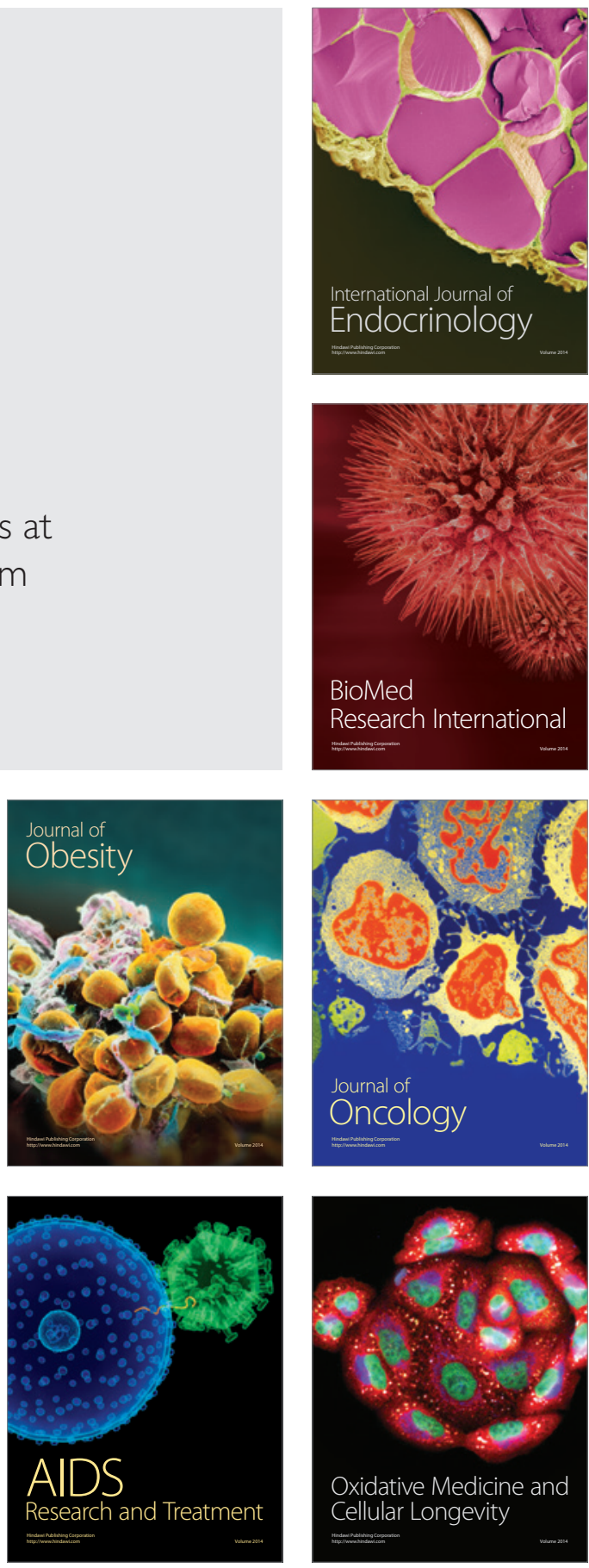